\title{
PEMBUATAN MEDIA PEMBELAJARAN BERBASIS VIDIO UNTUK GURU SEKOLAH DASAR KOTA PALANGKA RAYA
}

\author{
Roso Sugiyanto, Asih Utami, Andi Tenri Abeng \\ e-mail: rososugiyanto@gmail.com, Asih.utami@fkip.upr.ac.id \\ PGSD, FKIP, Universitas Palangka Raya
}

\begin{abstract}
ABSTRAK
Kegiatan pengabdian ini bertujuan untuk: 1) Menerapkan teknologi dalam membuat media pembelajaran yakni media pembelajaran berbasis vidio untuk siswa sekolah dasar (SD), dan 2) Menambah pengalaman belajar siswa yang menyenangkan. 3) Mendorong guru kreatif untuk membuat, dan mengembangkan media dengan teknologi sebagai penunjang menyajikan pembelajaran yang sesuai dengan perkembangan zaman. Hasil evaluasi diketahui bahwa 2 Guru $(22,2 \%)$ mampu melaksanakan/ mengoprasikan aplikasi dengan baik yaitu 15 langkah dalam mengoprasikan Wondershare filmora dan pada tingkat dasar, guru sudah mampu membuat multimedia dengan sederhana, 3 guru $(33,3 \%)$ cukup baik mampu menyelesaikan 14 langkah dari 15 langkah dalam mengoprasikan aplikasi Wondershare filmora, dan 4 guru (44,5\%) masih kurang baik dalam mengoprasikan aplikasi Wondershare filmora hanya menyelesaikan 5 sampi 8 langkah saja dari 15 langkah yang ada.
\end{abstract}

Kata kunci: Media pembelajaran, dan Vidio.

\begin{abstract}
This service activity aims to: 1) apply technology in making video-based learning media for elementary students, and 2) to add a pleasant student learning experience, 3 ) encouraging creative teachers to be mindful, and developing media with technology as a support to present learning in accordance with the times. The evaluation results revealed that 2 teachers $(22.2 \%)$ were able to carry out/ operate the application well which is 15 step in operating Wondershare filmora and at the basic level, the teacher has been able to make multimedia simply, 3 teachers $(33.3 \%)$ are good enough to complete 14 steps from 15 steps in operating Wondershare filmora application, and 4 teachers $(44.5 \%)$ are still not good at operate the Wondershare filmora application only complete 5 to 8 of the 15 steps.
\end{abstract}

Key words: learning media, and video

\section{PENDAHULUAN}

Proses pembelajaran yang dilakukan oleh guru di sekolah tidak bisa lepas dari pendekatan, metode, dan media yang diterapkan dalam proses pembelajaran. Guru yang baik akan memilih pendekatan, metode, dan media yang sesuai dengan dunia anak-anak sekolah dasar yang suka bermain. Ketepatan dalam memilih pendekatan, metode, dan media sangat besar pengaruhnya bagi anakanak sekolah dasar dalam berupaya menguasai materi pembelajaran.

Pendekatan, metode, dan media yang diterapkan dalam proses pembelajaran seharusnya sesuai dengan taraf berfikir anak sekolah dasar yang perkembangaan berfikirnya masih tahap komkrit. Ketepatan dalam memilih pendekatan, metode, dan media sangat besar pengaruhnya bagi anakanak sekolah dasar dalam berupaya menguasai materi pembelajaran. Penyampaian materi di SD tanpa media dan praktek langsung bagi anak sekolah dasar sangatlah sulit dalam menguasai konsep materi itu sendiri.

Anak sekolah dasar adalah anak usia 6-12 tahun dengan ciri-ciri belajar kecakapan fisik, membangun sikap menyeluruh terhadap diri 
sendiri,belajar bergaul dengan teman sebaya, belajar memainkan peran pria/wanita, mengembangkan kecakapan dasar baca, tulis, dan hitung. Mengembangkan konsep yang diperlukan sehari-hari, mengembangkan nurani, moralitas, dan nilai. Mencapai kemandirian pribadi, dan membentuk sikap terhadap kelompok dan lembaga social (Hurlock, 1978:40).

Menurut Hujair AH Sanaky (2009: 4) media pembelajaran adalah sarana pendidikan yang dapat digunakan sebagai perantara dalam proses pembelajaran untuk mempertinggi efektivitas dan efesiensi dalam mencapai tujuan pengajaran. Untuk itu setiap guru harus memiliki pengetahuan dan pemahaman yang cukup tentang media pendidikan. Sedangkan menurut (Etin Solihatin \& Raharjo, 2008: 22) media pembelajaran sebagai salah satu komponen pembelajaran, tidak dapat lepas dari pembahasan sistem pembelajaran secara menyeluruh.

Secara umum Ariani (2010: 26-

27) mengemukakan beberapa manfaat multimedia pembelajaran antara lain:

(1) Lebih menarik, (2) Lebih interaktif, (3) Jumlah waktu mengajar (ceramah) guru/pendidik dapat dikurangi, (4) Kualitas belajar siswa dapat lebih termotivasi dan terdongkrak, (5) Sikap dan perhatian belajar siswa dapat ditingkatkan dan dipusatkan, (6) Dapat menghidupkan teks dengan menyertakan bunyi, gambar, musik, animasi dan video, (7) Dapat menarik minat karena merupakan gabungan antara pandangan, suara dan gerakan.

Pemanfaatan media merupakan bagian yang harus mendapat perhatian guru dalam setiap kegiatan pembelajaran. Namun kenyataannya dilapangan (Sekolah Dasar Negeri 8 Palangka) media pembelajaran masih sering terabaikan dengan berbagai macam alasan, diantaranya terbatasnya waktu untuk membuat persiapan, sulit mencari media yang tepat, tidak adanya dana, tidak bisa membuat media yang bagus sesuai dengan perkembangan zaman dan lain sebagainya.

Adanya kegiatan Pembuatan Media Pembelajaran berbasis teknologi Vidio Filmora atau sejenisnya sangat diharapkan oleh guru-guru SD Negeri 8 Palangka Kota Palangka Raya sebagai solusi permasalahan yang terjadi di sekolahsekolah SD. Dengan adanya antusiasme guru, hal ini membuktikan bahwa kegiatan Pembuatan Media Pembelajaran berbasis teknologi Vidio Filmora sagatlah penting untuk memberdayakan mitra dengan melatih guru memiliki kemampuan membuat dan mengembangkan media pembelajaran yang kreatif.

\section{METODE PELAKSANAAN}

Kegiatan pengabdian masyarakat dilaksanakan di Sekolah Dasar Negeri 8 Palangka kota Palangka Raya selama 6 bulan terhitung mulai persiapan. Adapun metode pelaksanaan pengabdian masyarakat adalah dengan menjalin kerja sama dengan guru-guru di SD N 8 sebagai mitra. Berikut ini adalah langkah-langkah kegiatan yang dilakukan dalam pengabdian masyarakat:

Pengabdian ini merupakan kegiatan pelatihan dan pendampingan. Kegiatan Pengabdian ini dilaksanakan dengan tiga tahap perencanaan, pelaksanaan (sosialisasi, pelatihan dan pendampingan) dan evaluasi. Tahap pertama kegiatan perencanaan meliputi pembuatan 
buku panduan membuat media pembelajaran berbasis tekhnologi dalam bentuk vidio dan koordinasi dengan pihak mitra mengenai kapan pelaksanaannya kegiatan pengabdian.

Tahap yang kedua kegiatan pelaksanaan pengabdian yang dilaksanakan dengan metode sosialisasi, pelatihan dan pendampingan. Tim pengusul pengabdian PKMS akan memberikan sosialisasi, pelatihan pada mitra (Guru-guru di SD Negeri 8 Palangka Kota Palangka Raya) agar bisa menghasikan produk berupa media pembelajara SD berbasis tekhnologi yang kreatif. Kegiatan kedua selanjutnya adalah pendampingan, kegiatana pendampingan yang dilaksanakan Tim pengabdian dengan menggunakan metode Pendampingan dan pembinaan yang dilakukan untuk melihat sejauh mana guru mampu mengembangkan serta menggunakan media pembelajaran berbasis teknologi vidio filmora dalam kegiatan belajar mengajar di sekolah. Tahap ketiga adalah kegiatan evaluasi yang dilaksanakan setelah kegiatan pelatihan selesai.

\section{HASIL DAN PEMBAHSAN}

Hal yang menjadi pertimbangan bahwa kegiatan pelatihan penting adalah media pembelajaran berbasis teknologi (Vidio) akan menjadi media alternatif dalam pembelajaran di sekolah, menjadi sarana mengatasi keterbatasan jumlah media yang ada dan guru kelas dalam mengajar di kelas, menjadi bagian strategi pembelajaran dalam upaya mengatasi penguasaan konsep pada siswa dengan cara lebih menarik, menyenangkan dan menambah semangat dalam belajar, dan menjadi media yang mudah digunakan oleh siswa, tidak membahayakan, dan menarik.

Kegiatan Pengabdian ini dilaksanakan dengan tiga tahap perencanaan, pelaksanaan (sosialisasi, pelatihan dan pendampingan) dan evaluasi.

1. Tahap Pertama. Kegiatan perencanaan meliputi pembuatan buku panduan membuat media pembelajaran berbasis tekhnologi dalam bentuk vidio dan koordinasi dengan pihak mitra mengenai kapan pelaksanaannya kegiatan pengabdian. Kegiatan pengabdian ini dilaksanakan dengan peserta seluruh guru yang ada di Sekolah Dasar Negeri 8 Palangka Kota Palangka Raya yang berjumlah 9 Orang guru dan 1 orang kepala sekolah. Pelaksanaan kegiatan pada tanggal 8 -12 Agustus 2018.

2. Tahap Kedua. Kegiatan pelaksanaan pengabdian yang dilaksanakan dengan metode sosialisasi, pelatihan dan pendampingan.

a. Tim pelaksana pengabdian PKMS akan memberikan sosialisasi terkait media pembelajaran.

b. Kegiatan pelatihan pembuatan media pembelajaran berbasis teknologi dengan menggunakan aplikasi "Wondeshare Filmora" agar mitra (Guru-guru di SD Negeri 8 Palangka Kota Palangka Raya) bisa menghasikan produk berupa media pembelajara SD berbasis teknologi yang kreatif.

Aplikasi Wondershare Video Editor merupakan aplikasi edit vidio yang mudah 
digunakan dan trendi. Karena aplikasi ini video editing software yang memungkinkan dapat menghasilkan video yang keren, terlepas dari tingkat keahlian penggunanya. Wondershare Video Editor memberikan bantuan untuk memulai dengan setiap proyek film yang baru dengan mengimpor dan mengedit video, menambahkan transisi dan efek khusus dan berbagi produksi akhir pada DVD, perangkat mobile atau web.

\section{Materi}

yang

disampaikan dalam kegitan pelatihan ini meliputi, sebagai berikut:

a). Pengenalan, b). Memulai, c). Menciptakan proyek, d). Impor dan mengatur Media, e). Pengeditan dasar, f). Pengeditan lanjutan, g). Menambahkan klip Overlay (PIP), h). Split layar, i). Scene deteksi, j). Bekerja dengan Audio, k). Insert transisi, 1). Menggunakan teks dan Intro/kredit, n). Menerapkan efek khusus, o). Menyimpan dan berbagi, dan p.) Hapus Watermark.
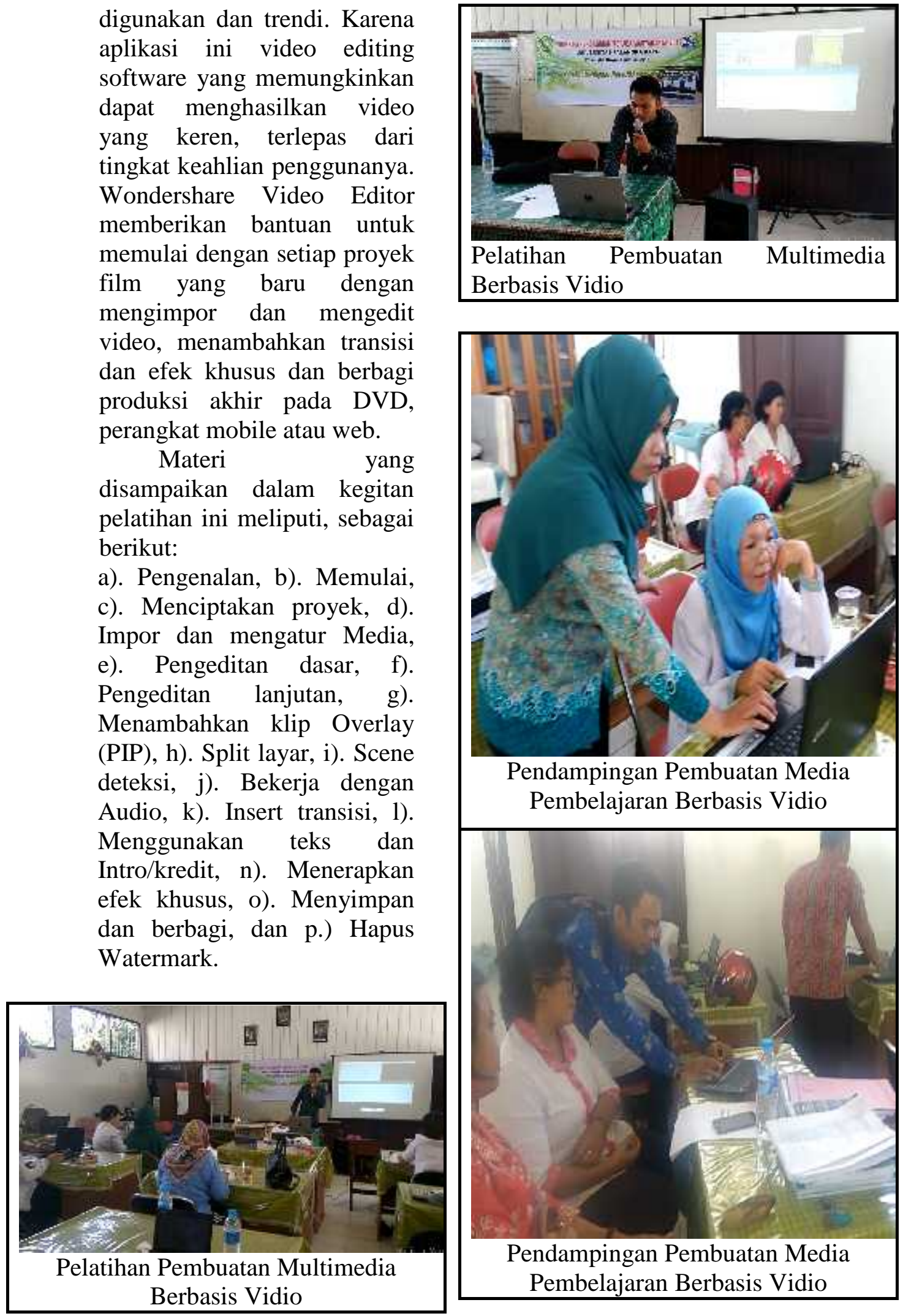
3. Tahap Ketiga. Kegiatan evaluasi dilakukan untuk melihat sejauh mana para peserta pelatihan mampu memahami dan mengoprasikan aplikasi dalam membuat media pembelajaran berbasis teknologi, dan bagaimana respon dari mitra kegiatan pengabdian yaitu Sekolah Dasar Negeri 8 Palangka Kota Palangka Raya. Kegiatan evaluasi dilaksanakan setelah kegiatan pelatihan selesai.

Hasil evaluasi kegiatan pengabdian memperlihatkan bahwa ada 2 Guru (22,2\%) mampu melaksanakan/ mengoprasikan aplikasi dengan baik dari 15 langkah dalam mengoprasikan Wondershare Video Editor yaitu (Pengenalan, Memulai, Menciptakan proyek, Impor dan mengatur Media, Pengeditan dasar, Pengeditan lanjutan, Menambahkan klip Overlay (PIP), Split layar, Scene deteksi, Bekerja dengan Audio, Insert transisi, Menggunakan teks dan Intro/kredit, Menerapkan efek khusus, Menyimpan dan berbagi dan Hapus Watermark) dan menghasilkan media pembelajaran secara sederhana.

Ada 3 guru $(33,3 \%)$ sudah cukup dalam mengoprasikan aplikasi yaitu dapat menyelesaikan 14 langkah dari 15 langkah dalam mengoprasikan aplikasi Wondershare Video Editor, untuk langkah (Hapus Watermark) tidak terlaksana dan para peserta juga tidak sampai menghasilkan media pembelajaran. Sedangkan 4 guru (44,5\%) masih kurang mampu dalam mengoprasikan aplikasi hanya dapat menyelesaikan 5 sampi 8 langkah saja dari 15 langkah dalam mengoprasikan aplikasi Wondershare Video Editor dan tidak menghasilkan media pembelajaran. Secara kuantitatif hasil kegiatan pelaksanaan pelatihan dapat dilihat pada tabel 3, di bawah.

\section{Tabel 2. Rekapitulasi Kemampuan Guru} Membuat Media Pembelajaran

\begin{tabular}{|c|c|c|c|lcrc|}
\hline No & Kategori & F & \% & \multicolumn{4}{|c|}{ Keterangan } \\
\hline 1 & Baik & 2 & 22,2 & $\begin{array}{l}\text { Mampu mengoprasikan aplikasi 15 } \\
\text { langkah dan menghasilkan media } \\
\text { pembelajaran }\end{array}$ \\
\hline 2 & Cukup & 3 & 33,3 & $\begin{array}{l}\text { Mampu mengoprasikan aplikasi } \\
\text { langkah }\end{array}$ & 14 \\
\hline 3 & Kurang & 4 & 44,5 & $\begin{array}{l}\text { Mampu mengoprasikan aplikasi } \\
\text { langkah }\end{array}$ & 5-8 \\
\hline & & 9 & 100 & & & & \\
\hline
\end{tabular}

\section{KESIMPULAN}

Hasil evaluasi kegiatan pengabdian kepada masyarakat bahwa kegiatan berjalan lancar dan terlaksanan dengan baik. Hal ini terbukti dengan diketahui bahwa 2
Guru (22,2\%) mampu melaksanakan/ mengoprasikan aplikasi dengan baik yaitu 15 langkah dalam mengoprasikan Wondershare filmora dan menghasilkan media pembelajaran secara sederhana. 3 
guru $(33,3 \%)$ cukup baik mampu menyelesaikan 14 langkah dari 15 langkah dalam mengoprasikan aplikasi Wondershare filmora, dan 4 guru (44,5\%) masih kurang baik dalam mengoprasikan aplikasi Wondershare filmora hanya menyelesaikan 5 sampi 8 langkah saja dari 15 langkah yang ada.

\section{SARAN}

Berdasarkan kesimpulan sebagaimana tersebut di atas, maka dapat disarankan agar:

1. Diharapkan pemerintah lebih berperan aktif dalam pelaksanaan kegiatan pelatihan ataupun workshop dalam pembuatan media pembelajaran agar guru-guru di sekolah secara mandiri mampu membuat media pembelajaran yang sesuai dengan perkembangan zaman.

2. Bagi pihak Sekolah Dasar Negeri 8 Palangka Kota Palangka Raya terutama guru-guru kelas di harapkan dapat mengembangkan dan meningkatkan ketrampilan dalam membuat berbagai macam media senagai media pembelajaran menyenangkan sehingga tujuan pembelajaran dapat tercapai.

\section{DAFTAR PUSTAKA}

Ariani, N. \& Haryanto, D. (2010). Pembelajaran Multimedia di Sekolah. Jakarta: PT. Prestasi Pustakaraya.

Arsyad, A. (2007). Media Pembelajaran. Jakarta: PT Raja Grafindo Persada.
Azwar, (2008) Analisis Stimulus dan Fungsi Gambar dalam Buku Teks IPA dan IPS Sekolah Dasar. http://www.malang.ac.id/jip/index.ht $\underline{\mathrm{m}}$.

Depdiknas. (2006). Peraturan Pemerintah Pendidikan Nasional No 22, Tahun 2006, tentang Standar Isi Pendidikan.

Etin Solihatin \& Raharjo. (2008). Cooperative learning: Analisis model pembelajaran IPS. Jakarta: Bumi Aksara.

Hujair AH Sanaky. (2009). Media pembelajaran. Yogyakarta: Safiria Insania Press.

Hurlock, E.B. (1978). Perkembangan Anak Jakarata: Erlangga.

Nana Sudjana \& Ahmad Rivai. (2002). Media pengajaran. Jakarta: Sinar Baru Algensindo.

Oetomo, B.S.D. (2002). E-education; Konsep Teknologi dan Aplikasi Internet Pendidikan. Yogyakarta: Andi

Roso Sugiyanto, (2015). Pemanfaatan Media Lingkungan untuk Meningkatkan Hasil Beajar IPS Siswa SD Negeri Tanah Putih Kecamatan Telawang Kabupaten Kotawaringin Timur. Jurnal Geotadulako Vol.3 No.6. 2015: 30-40. 